\title{
First evidence of the mutations associated with pyrethroid resistance in head lice (Phthiraptera: Pediculidae) from Honduras
}

Kelsey Larkin ${ }^{1}$, Carol A. Rodriguez²,3, Shabana Jamani' , Georgina Fronza ${ }^{4}$, Gonzalo Roca-Acevedo ${ }^{4}$, Ana Sanchez ${ }^{1,3}$ and Ariel C. Toloza ${ }^{4 *}$

\begin{abstract}
Background: The human head louse, Pediculus humanus capitis, is a cosmopolitan blood-sucking ectoparasite affecting mostly schoolchildren in both developed and developing countries. In Honduras, chemical pediculicides are the first line of treatment, with permethrin as their main active ingredient. Despite the extended use of these products, there is currently no research investigating insecticide resistance in Honduran head lice. In head lice, the most common mechanism is knockdown resistance $(k d r)$, which is the result of two point mutations and the associated amino acid substitutions, T917I and L920F, within the voltage-sensitive sodium channel (VSSC).
\end{abstract}

Methods: Genomic DNA was extracted from 83 head lice collected in the localities of San Buenaventura and La Hicaca, Honduras. Polymerase chain reaction (PCR) was used to amplify a 332-bp fragment of the VSSC gene that contains a site affected by $C / T$ mutation which results in a T917l amino acid substitution on each human head louse genomic DNA fragments.

Results: The C/T non-synonymous mutation which results in the T917l kdr amino acid substitution was detected in both head lice populations at frequencies ranging between 0.45-0.5. Globally, the frequency of this substitution was 0.47. Of these, 5 (6.1\%) were homozygous susceptible and 78 (93.9\%) were heterozygotes. The kdr-resistant homozygote (RR) was not detected in the studied populations. Thus, $93.9 \%$ of the head lice collected in Honduras harbored only one T917I allele. Exact test for the Hardy-Weinberg equilibrium for both localities showed that genotype frequencies differed significantly from expectation. In addition, San Buenaventura and La Hicaca populations had an inbreeding coefficient $\left(F_{i s}\right)<0$, suggesting an excess of heterozygotes.

Conclusions: To our knowledge, this is the first study showing the presence of the $\mathrm{C} / \mathrm{T}$ mutation responsible of the T917l kdr allele associated with pyrethroid resistance in $P$. h. capitis from Honduras. The PCR-restriction fragment length polymorphism (RFLP) employed here has demonstrated to be a reliable, economic, and reproducible assay that can be used to accurately genotype individual head lice for the mutation encoding the resistance-conferring T917I amino acid substitution. This highlights the necessity of proactive resistance management programmes designed to detect pyrethroid mutations before they become established within populations of head lice.

Keywords: Pediculus humanus capitis, Insecticide resistance, kdr, Voltage-sensitive sodium channel, Pyrethroid, Honduras

*Correspondence: atoloza@conicet.gov.ar

${ }^{4}$ Centro de Investigaciones de Plagas e Insecticidas (UNIDEF-CONICET),

Villa Martelli, Argentina

Full list of author information is available at the end of the article

c) The Author(s) 2020. This article is licensed under a Creative Commons Attribution 4.0 International License, which permits use, sharing, adaptation, distribution and reproduction in any medium or format, as long as you give appropriate credit to the original author(s) and the source, provide a link to the Creative Commons licence, and indicate if changes were made. The images or other third party material in this article are included in the article's Creative Commons licence, unless indicated otherwise in a credit line to the material. If material is not included in the article's Creative Commons licence and your intended use is not permitted by statutory regulation or exceeds the permitted use, you will need to obtain permission directly from the copyright holder. To view a copy of this licence, visit http://creativeco mmons.org/licenses/by/4.0/. The Creative Commons Public Domain Dedication waiver (http://creativecommons.org/publicdomain/ zero/1.0/) applies to the data made available in this article, unless otherwise stated in a credit line to the data. 


\section{Background}

Pediculus humanus capitis De Geer, commonly known as the human head louse, is a cosmopolitan and obligate ectoparasite found both in developed and developing countries. Head lice infestation is known as pediculosis capitis which can result in pruritus, loss of sleep, attention deficit, and is associated with secondary skin infections due to scratching of an irritated scalp [1]. Head lice are transmitted by direct host-to-host contact, and are heavily influenced by both social and behavioral transmission factors in children 4-13 years-old [2]. Despite the fact that head lice do not possess a disease vector status, they have been found to carry bacteria associated with typhus (only under controlled experimental conditions), trench-fever, and hospital acquired infections [3-6].

The control of pediculosis among populations comprises both individual and collective approaches. The former includes the use of mechanical or chemical methods, while the latter is based on limiting exposure through behavioral modifications. Specific treatment for this infestation relies heavily on the topical use of pediculicides, compounds with toxic or otherwise deleterious effects to lice. Traditionally, pediculicides containing a wide variety of insecticides such as DDT, lindane, carbaryl, malathion, $d$-phenothrin, and permethrin have been employed to treat head lice infestations worldwide [7]. Chemical pediculicides are still recommended as first line of treatment worldwide and consist of over-the-counter (OTC) products, as well as products only available under medical prescription.

With sales over 200 million USD per year in the USA market alone, the global industry for topical OTC products play a significant role in the control of this infestation [8]. The most frequently used pediculicides are topical formulations, notably those containing pyrethroids and organophosphates as their main active ingredients. Of these, pyrethroids are the most widely used due to the shorter exposure time, less odor, lower mammalian toxicity, and relatively safe environmental persistence. However, the intensive and continuous use of this class of insecticide has led to the development of resistance, ultimately hindering control strategies in several countries like Denmark, UK, France, Israel, Argentina, USA, México, Russia and Chile [4, 9-16].

Pyrethroid resistance is perhaps the single most important factor for the increased prevalence of head lice infestations worldwide $[17,18]$. Lice resistant to pyrethroids possess "knockdown" resistance $(k d r)$, caused by single nucleotide point mutations (SNPs) in the para-orthologous voltage-sensitive sodium channel (VSSC) gene, which result in reducing nerve sensitivity to the insects. It has been clearly established that the primary amino acid substitution, T917I and L920F, located in domain II, are responsible for resistance [19]. A number of other mutations have been reported, but they are not good candidates as molecular markers of resistance. The mutation D11E is unlikely to be involved in insensitivity of the sodium channel, as it is conservative, located in an N-terminal inner membrane segment, and found in susceptible body lice [20]. Mutations T929I and L932F, which have been reported as associated with permethrin resistance were in fact expressed in the amino acid sequence positions of the house fly VSSC (rather than in the head louse amino acid sequence). Moreover, it has been demonstrated that these mutations coexist en bloc as a resistant haplotype, and when T197I was expressed in Xenopus oocytes either alone or in combination, virtually suppressed permethrin sensitivity. A body of evidence points to the relevance of T917I amino acid substitution in pyrethroid resistance via the $k d r$-type nerve insensitivity mechanism, and therefore can be used as a molecular marker for resistance detection [21].

In Honduras, a few authors have reported that pediculosis is a neglected and serious health problem affecting $10-83 \%$ of school-aged children from several regions [22-24]. Chemical lice control in Honduras is ubiquitous, with an abundance of pyrethrin and pyrethroid-based products in the market (e.g. pyrethrin 1\%, permethrin $1-4 \%$, and cypermethrin $0.2 \%$ ). Notwithstanding, there is a paucity of research on head lice, and no data about head lice insecticide resistance are available for Honduras. With the exception of anecdotal reports about the inefficacy of OTC pediculicides [24], whether insecticide resistance is emerging among head lice populations in the country remains unknown. The present study aimed to investigate the presence and distribution of the nonsynonymous mutation responsible of the T917I $k d r$ substitution in head lice from two localities of Honduras.

\section{Methods \\ Lice samples}

A total of 83 human head lice (adults and stage III nymphs) were collected from children residing in two Honduran rural communities (La Hicaca and San Buenaventura) (Fig. 1). Lice were collected from heads of infested children using a dry-combing technique with the aid of an electric V-comb (ToLife Technologies, Welshpool, Australia), a stainless-steel metal comb that utilizes suction power to trap head lice and nits into single-use filters [24]. An adjustable headset with magnifying lenses (MG81001-G-2 led Headband illuminating Magnifier 2; ToLife Technologies) to inspect the head in order to identify the different insect stages was used. Stainless steel tweezers were used to collect live lice that were trapped in the head of the $\mathrm{V}$-comb. Overall inspection 


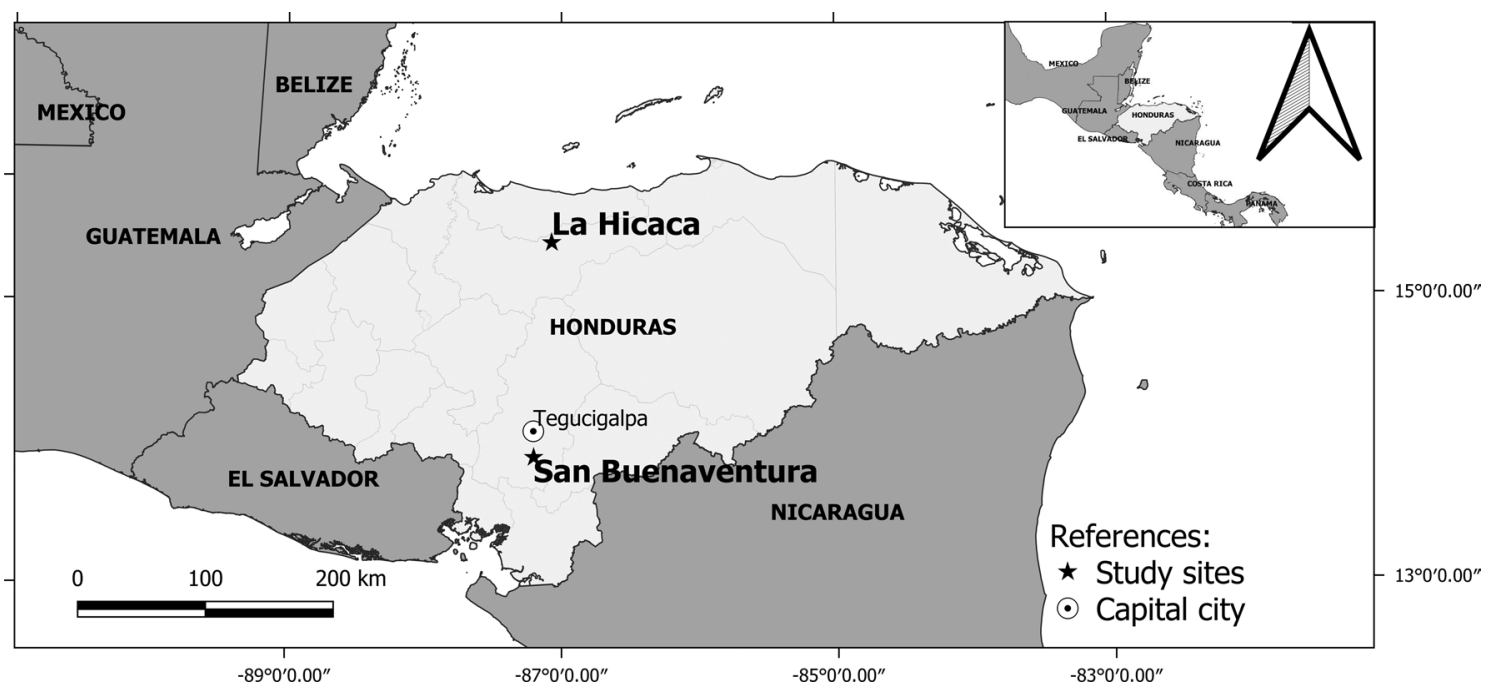

Fig. 1 Geographical location of the head louse populations from Honduras

of the whole head was around 20-30 min, depending on hair length and thickness. Between inspections, the head of the V-comb, hair clips, and tweezers were sanitized in $10 \%$ bleach solution and rinsed with clean water. Then, lice were transferred from the filters into vials containing $70 \%$ ethanol. Once in the laboratory, insects were stored at $4{ }^{\circ} \mathrm{C}$ until studied

\section{Extraction of genomic DNA and PCR amplification of the $k d r$-fragment}

Genomic DNA was isolated from individual adults and nymphal stage III head lice following the methodology of Ascunce et al. [25]. In short, each louse was cut in half using a scalpel, placed in a $1.5 \mathrm{ml}$ Eppendorf tube containing cell lysis solution and proteinase $\mathrm{K}$, then homogenized using a sterile plastic pestle. DNA was extracted from each individual louse using the Wizard genomic DNA purification kit (Promega, Madison, WI, USA) following the manufacturer's protocol for insect tissues. After extracting the DNA, a dilution from the original concentration to $\approx 5-10 \mathrm{ng} / \mu \mathrm{l}$ was made.

The RFLP method employed here uses genomic DNA to discriminate between resistant and susceptible VSSC gene alleles in head lice and as described by Kristensen et al. [9]. This method allows for easy discrimination of three genotypes (homozygous susceptible, heterozygous and homozygous resistant) by the number and size of electrophoretic bands detected in an agarose gel. Other advantages of this method include cost-effectiveness, efficiency and reliability. Most importantly, this method allows zygosity detection, which is particularly relevant in epidemiological studies [11].
Polymerase chain reaction (PCR) was used to amplify a 332-bp fragment of the VSSC gene that contains a site affected by a $\mathrm{C} / \mathrm{T}$ mutation corresponding to the T917I amino acid substitution on each human head louse genomic DNA fragments [11].

Reactions consisted of a total volume of $25 \mu \mathrm{l}$ including $12.5 \mu \mathrm{l}$ MasterMix (Promega), $1 \mu \mathrm{l}(0.25 \mu \mathrm{M})$ of each primer (sense: 5'-AAT CGT GGC CAA CGT TAA A-3'; antisense: 5'-TGA ATC CAT TCA CCG CAT AA-3'), $2 \mu$ of total genomic DNA, and $8.5 \mu \mathrm{l}$ of $\mathrm{ddH}_{2} \mathrm{O}$ [13]. The PCR reactions were programmed as follows: $94{ }^{\circ} \mathrm{C}$ for $10 \mathrm{~min} ; 40$ cycles of $94{ }^{\circ} \mathrm{C}$ for $30 \mathrm{~s}, 56{ }^{\circ} \mathrm{C}$ for $30 \mathrm{~s}, 65{ }^{\circ} \mathrm{C}$ for $1 \mathrm{~min}$; and a final extension step at 65 ${ }^{\circ} \mathrm{C}$ for $10 \mathrm{~min}$. Then, $10 \mu \mathrm{l}$ of each PCR amplicon was digested with $10 \mathrm{U}$ of $S s p$ I restriction enzyme (Thermo Fisher Scientific, Waltham, USA) at $37{ }^{\circ} \mathrm{C}$ to determine the AAT ATT restriction site. Digested fragments were separated using $2 \%$ agarose gel electrophoresis, visualized by staining with ethidium bromide, and analyzed after being photographed under UV light.

\section{Statistical analysis of genotype frequencies}

Genotype frequencies were calculated by dividing the number of lice of each genotype (RR, RS and SS) by the total number of analyzed head lice. Then, genotype frequencies at the 917 locus were tested to fit the Hardy-Weinberg (H-W) expectations using the program Genepop (v. 4.2) [26], option 1 (Hardy-Weinberg exact tests), sub-option 3 (probability test; [26]). This software was also used to estimate Wright's inbreeding coefficient $\left(\mathrm{F}_{\text {is }}\right)[26]$ and for populations out of the H-W equilibrium. These values were employed to test for heterozygote 
deficiency and excess (Genepop option 1, sub-options 1 and 2, respectively) using the $\mathrm{U}$ test as described in Raymond et al. [27].

\section{Results}

We identified and determined the presence of the T917I $k d r$ substitution in all 83 head lice collected (Table 1). The diagnostic genetic marker linked to permethrin resistance consists of the presence of one or two fragments after the digestion with SspI. The occurrence of the nucleotide substitution of the $\mathrm{C} \rightarrow \mathrm{T}$ that codes for the T917I substitution results in a unique cutting site of this restriction endonuclease in the $k d r$-fragment. Thus, three possible amplified fragments leading to three head louse genotypes were found: a homozygous susceptible or wild-type allele- (SS) identified by a fragment of $332 \mathrm{bp}$; the heterozygote (RS) with three fragments of 332, 261 and $71 \mathrm{bp;} \mathrm{and} \mathrm{a} \mathrm{homozygous} \mathrm{resistant} \mathrm{mutant}$ allele-identified by two bands of 261 and $71 \mathrm{bp}$. Globally, the frequency of the T917I substitution was 0.47 in the two head louse populations (La Hicaca and San Buenaventura) of Honduras. Both lice populations possessed $k d r$-like alleles with a medium frequency of 45.6 and $50 \%$, respectively. Of these, $5(6.1 \%)$ were homozygous susceptible and 78 (93.9\%) were heterozygotes. The $k d r$ resistant homozygote (RR) was not detected in the studied populations. Thus, $93.9 \%$ of the head lice collected in Honduras harbored only one T917I mutant allele.

The exact test for the Hardy-Weinberg equilibrium for both localities showed that genotype frequencies differed significantly from expectation. In addition, San Buenaventura and La Hicaca populations had an inbreeding coefficient $\left(\mathrm{F}_{\mathrm{is}}\right)<0$, suggesting an excess of heterozygotes (Table 1).

\section{Discussion}

Prevalence of head lice infestation varies considerably among populations, with factors such as gender, age, and sociocultural characteristics driving important differences within populations. Despite the label of "neglected tropical disease", pediculosis is prevalent in both highincome societies as well as resource-poor countries [18]. Control of pediculosis in schools and day care settings are based on health education, early diagnosis, and prompt treatment of infested children. Among the diversity of removal and treatment methods (fine-tooth combing, household products, heat application, oral treatment, and topical insecticides), permethrin remains as the popular chemical compound for the treatment of head lice infestations worldwide. Since the launching of permethrin as an OTC product in the 1980s, its extensive and intensive use for over 30 years has exerted a strong selective pressure on over exposed insect populations across the world [28].

To the best of our knowledge, this is the first study analyzing the permethrin resistance status of $k d r$-type mutations in head lice from Honduras. The frequency of the $k d r$ molecular marker was at 0.4698 , with an overall mean of $46.95 \%$ for the heterozygous lice (RS). These values are in accordance with those found in head lice collected in schoolchildren from Wales and Chile [10, 16]. In these studies, the global percentage of the T917I substitution was 0.43 and 0.50 , with 77.2 and $88.8 \%$ of the lice characterized as heterozygous; respectively. Despite the similar trend of the $k d r$ mutant allele occurrence in the $P . h$. capitis from Wales, Chile and Honduras, the frequency of pyrethroid resistance gene is highly variable and widespread. A world $k d r$ map of head louse populations from 14 countries, including North and South America, Asia, the European Union, Oceania, and Africa showed an overall resistance allele frequency ranging between $29-100 \%$ [29]. This indicates that geographical variability is highly fluctuating and is exclusively dependent on the selective pressure induced by the use of pyrethroids to treat pediculosis.

In Honduras, research on head lice infestation is scarce, with only three studies available in the literature [22-24]. In these investigations, reported prevalence of head lice varied from 10 to $83 \%$, which is well above the overall $5 \%$ epidemiological value considered to be of epidemic

Table 1 Distribution of $k d r$-like alleles T917l in head lice populations from Honduras

\begin{tabular}{|c|c|c|c|c|c|c|c|}
\hline \multirow[t]{2}{*}{ Population } & \multirow{2}{*}{$\begin{array}{l}\text { No. of head lice analyzed (no. } \\
\text { of infested subjects) }\end{array}$} & \multicolumn{3}{|c|}{ Genotype $^{a}$} & \multirow{2}{*}{$\begin{array}{l}\text { Resistance allele } \\
\text { frequency (\%) }\end{array}$} & \multirow[t]{2}{*}{$H-W^{b}\left(x^{2}\right)$} & \multirow[t]{2}{*}{$F_{i s}^{d}$} \\
\hline & & $S / S$ & $R / S$ & $R / R$ & & & \\
\hline San Buenaventura & $25(8)$ & 0 & $25(100)$ & 0 & 50 & $25^{c}$ & $-1^{c}$ \\
\hline La Hicaca & $58(12)$ & $5(8.6)$ & $53(91.4)$ & 0 & 45.68 & $41.04^{c}$ & $-0.83^{c}$ \\
\hline Total & $83(20)$ & $5(6.1)$ & 78 (93.9) & 0 & 46.98 & $65.2^{c}$ & $-0.887^{c}$ \\
\hline
\end{tabular}

\footnotetext{
${ }^{a} \mathrm{~S}$ and $\mathrm{R}$ are susceptible and resistant alleles. Between brackets are the percentages of each genotype proportion

b Populations were tested for the Hardy-Weinberg equilibrium by a chi-square test $\left(X^{2}=3.84, d f=2, P<0.05\right)$

c Values that are statistically significant at $P<0.05$. Significance level indicates rejection of the null hypothesis $F_{\text {is }}=0$ at $P<0.05$

${ }^{d} F_{\text {is }}$ values $>0$ indicate heterozygote deficiency, whereas $F_{\text {is }}$ values $<0$ indicate heterozygote excess
} 
importance [30]. As in many countries, pediculosis is a neglected infestation in Honduras which is not prioritized in national or regional public health programmes. In fact, ectoparasitic diseases are included in the strategic plan for the prevention, attention, control, and elimination of neglected infectious diseases in Honduras [24]. Currently, permethrin and cypermethrin are the most commonly used OTC pediculicides in the country, with permethrin being the most available compound with $83 \%$ of the market share (CAR, personal communication). As a result, head lice remain exposed to pyrethroid-based pediculicides at a high selective pressure. An exact test for the Hardy-Weinberg equilibrium showed that genotype frequencies differed significantly from expectation in all the studied populations. The deficiency of both susceptible (5 per 83 ) and resistant homozygous ( 0 per 83 ), and the over-representation of heterozygotes (78 per 83 ), suggests that the head lice populations of Honduras are currently under active selective pressure.

Similarly, the pattern detected in Honduran specimens was also found in head lice from school children of Wales and Chile. For instance, the study performed in Wales showed that of the 316 analyzed lice, 55 were homozygous susceptible, 17 were homozygous resistant and 244 were heterozygotes [10]. In Chile, $5 \%$ and $6.1 \%$ were both homozygous susceptible and resistant, and $88.9 \%$ were heterozygotes [16]. Conversely, head lice collected from France, Argentina, USA and Russia harbored a high frequency of homozygous $k d r$-type mutations suggesting that these alleles are strongly established and almost in fixation $[4,11,13,14,31]$. The evolutionary pattern found in the Honduran head lice suggests that if the selective pressure exerted by the pediculicides continue, it is highly probable that the $k d r$-type mutations might increase their frequency and reach fixation.

There are two possible explanations that might help to understand the excess of heterozygotes (93.9\%) reported in the present study. The first and the most conservative option is that $k d r$-mutations possess little or no effect on the overall fitness of the individuals, resulting in a slow return of the resistant population to the susceptible state. In other words, the resistant alleles might persist in high frequency within populations $[32,33]$. Permethrin resistance via $k d r$ mutations was not associated with any fitness disadvantage in head lice from the USA [34]. It could be speculated that head lice have developed means to minimize any fitness disadvantage associated with these resistance mutations. Because the two mutations exist en block as a resistant haplotype, the occurrence of the mutation (L920F) may function to compensate for any fitness disadvantage related with the (T917I) amino acid substitution in permethrin-resistant head lice [21]. This suggests that in an environment with no insecticide pressure, lice harboring the $k d r$-like alleles can compete equally with those who lack the mutations (wild type individuals) [35]. The second option to explain the excess of heterozygotes is that there may be a significant fitness cost associated with this genotype. Lice harboring only one copy of the $k d r$ mutation may have higher chances to survive under a selective environment compared to lice carrying two copies of the mutation.

A study in Burkina Faso found that heterozygote Anopheles gambiae male mosquitoes had a fitness advantage over the homozygote susceptible ones [36]. In that study, heterozygote males had higher mating success than either resistant or susceptible homozygotes, suggesting of a heterozygote advantage effect of the $k d r$ mutation in An. gambiae. Specifically, this research showed that there is a fitness cost related to possessing double alleles of the 1014F mutation rather than having just one allele. The swarms where the mosquitoes segregated to mate were predominantly composed of homozygote resistant males; however, the heterozygous males were more frequently selected by females for mating. This reduced mating success in homozygote RR $k d r$ males, affecting the neural network of the VSSC, consequently impairing some physiological traits such as mobility, perception of stimuli, and detection of olfactory signals. Reduced fitness of homozygous RR $k d r$ males would play a significant role in slowing down the expansion of resistance allele L1014F in the wild mosquito populations [37].

Considering that permethrin resistance is mainly mediated by $k d r$ mutations, and is determined by the intensity and frequency of the control measures employed to control pediculosis, different strategies could be implemented. In head lice populations where resistance is low or near zero, pyrethroids should continue to be used in conjunction (if possible) with resistance-monitoring programmes. On the contrary, in populations with high resistance levels, pyrethroids should be discontinued and replaced by products with different modes of action. Finally, in populations with intermediate allele frequency, as is the case in Honduras, it is imperative to implement insecticide-resistance programmes through the monitoring and prevention of head lice infestations.

For the establishment of an adequate resistance management programme, it is essential to detect early levels of insecticide resistance while at the same time preventive measures to avoid its spread are promoted. Early resistance detection by traditional toxicological bioassay-monitoring methods is highly recommended but impractical and difficult to operationalize. To overcome these limitations, the PCR-restriction fragment length polymorphism (RFLP) employed in the present work has demonstrated to be a reliable, economic, reproducible assay that can be used to accurately genotype 
individual head lice for the resistance-conferring T917I mutation.

The findings presented here support the need for more basic and implementation research in Honduras. Of crucial importance is the creation of regional health surveillance programmes focusing on head lice and their control.

Finally, there is an urgent need to increase awareness among the population and health care providers of the dangers of using harmful products and products not labeled to treat human pediculosis. Implementing this recommendation would considerably eliminate the unnecessary overexposure of children to pesticides in order to reduce both acute and chronic intoxications.

\section{Conclusions}

To the best of our knowledge, the findings of this work show for the first time that the T917I $k d r$ substitution was detected in two head lice populations from Honduras, with an overall frequency of 0.47. Distribution of $k d r$ genotypes differed significantly from Hardy-Weinberg proportions. Thus, deficiency of susceptible (6.1\%), lack of resistant (0\%) homozygous, and the overrepresentation of heterozygotes $(93.9 \%)$ suggests that the studied populations of head lice of Honduras are currently under active selective pressure of pyrethroids. This highlights the need for proactive resistance management programmes designed to detect pyrethroid mutations before they become established within populations of head lice.

\footnotetext{
Abbreviations

kdr: knockdown resistance; PCR: polymerase chain reaction; RFLP: restriction fragment length polymorphism; VSSC: voltage-sodium sensitive channel; OTC: over-the-counter; SNP: single nucleotide polymorphism.
}

\section{Acknowledgements}

We wish to thank Maritza Canales and Maria Mercedes Rueda for their assistance in collecting some of the head lice. Dr Romina Piccinali improved the final version of this manuscript. AT and GRA are members of the CONICET Research Category.

\section{Authors' contributions}

ACT and AS conceived and designed the experiments. KL, GF and GRA performed the experiments. ACT, GRA and GF designed the graphs and analyzed the data. CAR, SJ and AS performed the head lice collection. ACT and AS wrote the manuscript. All authors read and approved the final manuscript.

\section{Funding}

This study was supported by the CONICET award PIP-0198CO to ACT, and Agencia Nacional de Promoción Científica y Tecnológica (Argentina), PICT2015-1023 to GRA.

\section{Availability of data and materials}

Data supporting the conclusions of this article are included within the article The datasets used and analyzed during the present study are available from the corresponding author upon reasonable request.

\section{Ethics approval and consent to participate}

This study was approved by the Research Ethics Board of both Brock University (\#15-248) and the National Autonomous University of Honduras (\#06-2016). Informed consent was obtained from parents before children participated in the study, and also verbal assent was required by the child if older than 7 years of age. Lice processing was approved by the protocol for lice collection and identification of the Centro de Investigaciones de Plagas e Insecticidas (CIPEIN-UNIDEF, Buenos Aires, Argentina; \#BA20061995ARG, June 1995).

\section{Consent for publication}

Not applicable.

\section{Competing interests}

The authors declare that they have no competing interests.

\section{Author details}

${ }^{1}$ Department of Health Sciences, Faculty of Applied Health Sciences, Brock University, St. Catharines, ON, Canada. ${ }^{2}$ School of Microbiology, National Autonomous University of Honduras (UNAH), Tegucigalpa, Honduras. ${ }^{3}$ Instituto de Investigaciones en Microbiología, Universidad Nacional Autónoma de Honduras, Tegucigalpa, Honduras. ${ }^{4}$ Centro de Investigaciones de Plagas e Insecticidas (UNIDEF-CONICET), Villa Martelli, Argentina.

Received: 13 February 2020 Accepted: 10 June 2020

Published online: 16 June 2020

\section{References}

1. Mumcuoglu KY, Gilead L, Ingber A. New insights in pediculosis and scabies. Expert Rev Dermatol. 2009:4:285-302.

2. Toloza A, Vassena C, Gallardo A, González-Audino P, Picollo MI. Epidemiology of Pediculosis capitis in elementary schools of Buenos Aires, Argentina. Parasitol Res. 2009;104:1295-8.

3. Bouvresse $S$, Socolovschi C, Berdjane Z, Durand R, Izri A, Raoult D, et al. No evidence of Bartonella quintana but detection of Acinetobacter baumannii in head lice from elementary schoolchildren in Paris. Comp Immunol Microbiol Infect Dis. 2011;34:475-7.

4. Eremeeva ME, Capps D, Winful EB, Warang SS, Braswell SE, Tokarevich NK, et al. Molecular markers of pesticide resistance and pathogens in human head lice (Phthiraptera: Pediculidae) from rural Georgia, USA. J Med Entomol. 2017:54:1067-72.

5. Sasaki T, Poudel SKS, Isawa H, Hayashi T, Seki N, Tomita T, et al. First molecular evidence of Bartonella quintana in Pediculus humanus capitis (Phthiraptera: Pediculidae), collected from Nepalese children. J Med Entomol. 2006:43:110-2.

6. Robinson D, Leo N, Prociv P, Barker SC. Potential role of head lice, Pediculus humanus capitis, as vectors of Rickettsia prowazekii. Parasitol Res. 2003;90:209-11.

7. Burgess IF. Human lice and their control. Annu Rev Entomol. 2004:49:457-81.

8. Clark JM. Determination, mechanism and monitoring of knockdown resistance in permethrin-resistant human head lice, Pediculus humanus capitis. J Asia Pac Entomol. 2009;12:1-7.

9. Kristensen M. Identification of sodium channel mutations in human head louse (Anoplura : Pediculidae) from Denmark. J Med Entomol. 2005:42:826-9.

10. Thomas DR, McCarroll L, Roberts R, Karunaratne P, Roberts C, Casey D, et al. Surveillance of insecticide resistance in head lice using biochemical and molecular methods. Arch Dis Child. 2006;91:777-8.

11. Durand R, Millard B, Bouges-Michel C, Bruel C, Bouvresse S, Izri A. Detection of pyrethroid resistance gene in head lice in schoolchildren from Bobigny, France. J Med Entomol. 2007;44:796-8.

12. Lindh J, Mumcuoglu KY. Molecular analysis of pyrethroid resistance in Pediculus humanus capitis from Israel. Trends Entomol. 2012;8:37-41.

13. Toloza AC, Ascunce MS, Reed D, Picollo MI. Geographical distribution of pyrethroid resistance allele frequency in head lice (Phthiraptera: Pediculidae) from Argentina. J Med Entomol. 2014;51:139-44. 
14. Gellatly KJ, Krim S, Palenchar DJ, Shepherd K, Yoon KS, Rhodes CJ, et al. Vector control, pest management, resistance, repellents expansion of the knockdown resistance frequency map for human head lice (Phthiraptera: Pediculidae) in the United States using quantitative sequencing. J Med Entomol. 2016;53:653-9.

15. Ponce-Garcia G, Villanueva-Segura K, Trujillo-Rodriguez G, RodriguezSanchez IP, Lopez-Monroy B, Flores AE. First detection of the $k d r$ mutation T929l in head lice (Phthiraptera: Pediculidae) in schoolchildren of the Metropolitan Area of Nuevo Leon and Yucatan, Mexico. J Med Entomol. 2017:54:1025-30.

16. Roca-Acevedo G, Del Solar Kupfer CP, Dressel Roa P, Toloza AC. First determination of pyrethroid knockdown resistance alleles in human head lice (Phthiraptera: Pediculidae) from Chile. J Med Entomol. 2019;56:1698-703.

17. Falagas ME, Matthaiou DK, Rafailidis PI, Panos G, Pappas G. Worldwide prevalence of head lice. Emerg Infect Dis. 2008;14:1493-4.

18. Heukelbach J. Management and control of head lice infestations. 1st ed. Bremen-London: Uni-Med Verlag AG; 2010.

19. Lee SH, Gao J-R, Sup Yoon K, Mumcuoglu KY, Taplin D, Edman JD, et al Sodium channel mutations associated with knockdown resistance in the human head louse, Pediculus capitis (De Geer). Pestic Biochem Physiol. 2003;75:79-91.

20. Gao JR, Yoon KS, Lee SH, Takano-Lee M, Edman JD, Meinking TL, et al. Increased frequency of the T929I and L932F mutations associated with knockdown resistance in permethrin-resistant populations of the human head louse, Pediculus capitis, from California, Florida, and Texas. Pestic Biochem Physiol. 2003;77:115-24.

21. Yoon KS, Symington SB, Hyeock Lee S, Soderlund DM, Marshall Clark J. Three mutations identified in the voltage-sensitive sodium channel a-subunit gene of permethrin-resistant human head lice reduce the permethrin sensitivity of house fly Vssc1 sodium channels expressed in Xenopus oocytes. Insect Biochem Mol Biol. 2008;38:296-306.

22. Figueroa J, Moncada V, Reyes O, Peña C, Kaminsky R. Pediculosis capitis: un problema de salud desatendido en Honduras. Rev méd hondur. 2012;80:102-6.

23. Hernández KC, Enamorado BC, Delgado LQ, Martel B, Sierra M, Espinoza I. Prevalencia de dermatosis en niños escolares en Honduras. Med Cutan Ibero Lat Am. 2016;44:177-82.

24. Jamani S, Rodríguez C, Rueda MM, Matamoros G, Canales M, Bearman G, et al. Head lice infestations in rural Honduras: the need for an integrated approach to control neglected tropical diseases. Int J Dermatol. 2019;58:548-56.

25. Ascunce MS, Toups MA, Kassu G, Fane J, Scholl K, Reed DL. Nuclear genetic diversity in human lice (Pediculus humanus) reveals continental differences and high inbreeding among worldwide populations. PLoS ONE. 2013;8:e57619.
26. Weir BS, Cockerham CC. Estimating F-statistics for the analysis of population structure. Evolution. 1984;38:1358-70.

27. Raymond M, Rousset F. An exact test for population diferentiation. Evolution. 1995;49:1280-3.

28. Durand R, Cannet A, Berdjane Z, Bruel C, Haouchine D, Delaunay P, et al Infestation by pyrethroids resistant bed bugs in the suburb of Paris, France. Parasite. 2012;19:381-7.

29. Hodgdon HE, Yoon KS, Previte DJ, Kim HJ, Aboelghar GE, Lee SH, et al. Determination of knockdown resistance allele frequencies in global human head louse populations using the serial invasive signal amplification reaction. Pest Manag Sci. 2010;66:1031-40.

30. Clore ER. Nursing management of pediculosis. Pediatr Nurs. 1998;3:3-13.

31. Durand R, Bouvresse S, Andriantsoanirina V, Berdjane Z, Chosidow O, Izri A. High frequency of mutations associated with head lice pyrethroid resistance in schoolchildren from Bobigny, France. J Med Entomol. 2011;48:73-5.

32. Roush RT, McKenzie JA. Ecological genetics of insecticide and acaricide resistance. Annu Rev Entomol. 1987:32:361-80.

33. Yu SJ. The toxicology and biochemistry of insects. 2nd ed. Florida: CRC Press; 2014.

34. Takano-Lee M, Yoon KS, Edman JD, Mullens BA, Clark JM. In vivo and in vitro rearing of Pediculus humanus capitis (Anoplura: Pediculidae). J Med Entomol. 2003;40:628-35.

35. Grayson ML, Cosgrove SE, Crowe S, Hope W, McCarthy JS, Mills J, et al. Kucers' the use of antibiotics: a clinical review of antibacterial, antifungal, antiparasitic, and antiviral drugs. 7th ed. Boca Raton: CRC Press; 2017.

36. Platt N, Kwiatkowska RM, Irving H, Diabaté A, Dabire R, Wondji CS. Targetsite resistance mutations ( $k d r$ and $R D L$ ), but not metabolic resistance, negatively impact male mating competiveness in the malaria vector Anopheles gambiae. Heredity. 2015;115:243-52.

37. Rivero A, Vézilier J, Weill M, Read AF, Gandon S. Insecticide control of vector-borne diseases: when is insecticide resistance a problem? PLoS Pathog. 2010;6:e1001000.

\section{Publisher's Note}

Springer Nature remains neutral with regard to jurisdictional claims in published maps and institutional affiliations.

Ready to submit your research? Choose BMC and benefit from:

- fast, convenient online submission

- thorough peer review by experienced researchers in your field

- rapid publication on acceptance

- support for research data, including large and complex data types

- gold Open Access which fosters wider collaboration and increased citations

- maximum visibility for your research: over $100 \mathrm{M}$ website views per year

At BMC, research is always in progress.

Learn more biomedcentral.com/submissions 